\title{
Inverted Yield Curves and the Incidence of Recession: A Graphical Presentation
}

\author{
X. Henry Wang and Bill Z. Yang
}

\begin{abstract}
This paper attempts to explain why an inverted yield curve may be a leading indicator of recession. It develops a modified version of the extended IS-LM model with the term structure of interest rates and provides a phase-diagram analysis to illustrate how an adverse shock may result in an inverted yield curve as well as a subsequent recession. It demonstrates that the occurrence of inverted yield curve is an off-equilibrium phenomenon after an adverse shock in the adjustment process of interest rate and output, and that an inverted yield curve may lead, but does not lead to, a recession.
\end{abstract}

Index Terms-Inverted yield curve, IS-LM model, recession, term structure of interest rate.

\section{INTRODUCTION}

It has been well documented in the literature that the yield curve serves as a leading indicator of output with most being empirical studies (e.g., Estrella and Hardouvelis [1], Estrella and Mishkin [2], among others).2 Theoretical research to explain such a very interesting observation seems to have lagged behind until Estrella [4], to our knowledge. It is a subject of macroeconomics that examines the connection between interest rates and real economic activities. Thus, it suggests that the IS-LM setup is an innate candidate in modeling to investigate the issue. Since it involves the discrepancy between the short-term interest rate and the long-term interest rate, it also proposes that the term structure of interest rates should be introduced into the IS-LM model to study why an inverted yield curve may signal a following recession.

This note studies how and why the yield curve may serve as a leading indicator of real economic activities in a graphic model. We employ and modify the extended IS-LM model with the term structure of interest rates introduced in

Manuscript received October 15, 2010. This work was supported in part by the Summer (2010) Research Grant from the School of Economic Development, Georgia Southern University.

$\mathrm{X}$. Henry Wang is a professor at the Department of Economics, University of Missouri-Columbia, Columbia, MO 65211 USA (e-mail: WangX@missouri.edu).

Bill Z. Yang is an associate professor at the School of Economic Development, Georgia Southern University, Statesboro, GA 30460 USA. (912-478-5727; Fax: 912-478-0710; e-mail: billyang@georgiasouthern. edu).

${ }^{1}$ Berk [3] gave an excellent survey on this issue, and Estella [5] provided an informal summary in the form of FAQ's, including an extensive bibliography

${ }^{2}$ Berk [3] gave an excellent survey on this issue, and Estella [5] provided an informal summary in the form of FAQ's, including an extensive bibliography.
Blanchard and Fischer [6]. As a complement to Estella [4], we attempt to provide a visualversion to illustrate explicitly why an inverted yield curve may be a signal of a subsequent recession. We demonstrate that the occurrence of inverted yield curve is an off-equilibrium phenomenon during the process of adjustment in output and interest rates after an adverse shock, in particular, in the money market. As in the standard equilibrium and comparative static analysis, an adverse shock, real or monetary, causes the IS curve or the LM curve to shift. While the consequent equilibrium stands for the recession that follows, it is the adjustment path of the triplet - the output, the long rate and the short rate - that illustrates how and why the yield curve becomes inverted prior to the succeeding recession after the adverse shock. Therefore, an inverted yield curve may lead, but does not lead to, a recession, because they both are the results of the adverse shock one after the other.

Our analysis differs from the previous studies with a similar framework (e.g., Blanchard and Fischer [6], Fisher and Turnovsky [7], among others) in several aspects. First, we explicitly present both the long-term interest rate and the short-term interest rate in the picture and equations, instead of eliminating the short rate to examine a reduced form of the model. Second, to portray the shape of a yield curve, we assume that the short-term rate is always on the LM curve, though the long-term interest rate is on the IS curve only at equilibrium and can be away from the IS curve when it is off equilibrium. This point of view allows us to see directly the relative positions between the two interest rates that characterize the shape of the yield curve in the model. Third, the dynamic adjustment process in the long-term interest rate is driven by the resultant of two component forces: the market forces in the loanable funds market as well as the connection between the long rate and the short rate tied by the term premium and the expectations (see, e.g., Hubbard [8], Ball [9], among others). The resultant of the two forces induces the long-term rate to adjust toward the equilibrium, which is globally stable. This property is in contrast to the results of a saddle-point equilibrium in the previous studies that feature the adjustment process of the long-term interest rate by term premium and expectations. Fourth, our analysis does not rely on the assumption that the long-term bond is a consol; rather, the long-term rate canbe of any kind of long-term bonds without further specification.

One of the key assumptions in our analysis is that the short-term interest rate is always on the LM curve. It is plausible, however, and can be justified by the fact that most central banks employ the short-term interest rate rather than money supply as the tool in conducting monetary policy. 
Hence, once the targeted short-term interest rate is announced, the central bank will adjust the money supply to ensure the interest rate as targeted. This is exactly the practice of the Federal Reserve of the U.S., for example. Theoretically, the LM curve in our model essentially becomes the "monetary policy (MP) curve" as labeled in more recent macroeconomics and monetary economics literature and textbooks.3

Another interesting dimension of our model is how we characterize the dynamic adjustment process of the long-term interest rate. We borrow the concepts of component and resultant forces from physics. One driving force to move the long-term interest rate is the market mechanism of supply and demand in the loanable funds market, while the other is the term structure that links the long-term interest rate to the short-term interest rate in terms of the preferred habitat theory and the expectations theory. This treatment helps illustrate why and when a monetary policy may be as effective on the long rate as intended and when it is not so. Either way, it allows us to manifestly get the picture why an inverted yield curve may arise prior to a recession.

\section{AN IS-LM MODEL WITH TERM STRUCTURE}

It is assumed that price level is rigid as in a conventional short-run, closed-economy macroeconomic model (Carlson and Spencer [11]; Cebula [12]) when analyzing an issue on business cycle and stabilization policy. There are two markets: the loanable-funds (or equivalently, the product) market (IS) and the short-run money market (LM). Formally, we have

IS: $\quad \mathrm{Y}=\mathrm{C}(\mathrm{Y}-\mathrm{T})+\mathrm{I}(\mathrm{R})+\mathrm{G}$

LM: $\quad \mathrm{M} / \mathrm{P}=\mathrm{L}(\mathrm{r}, \mathrm{Y})$

Term structure of interest rates:

$$
R=\tau+(1-\alpha) r+\alpha E(r)
$$

where $\mathrm{Y}=$ output, $\mathrm{R}=$ real long-term interest rate, and $\mathrm{r}=$ real short-term interest rate, $\mathrm{T}=\operatorname{tax}, \mathrm{G}=$ government spending, $\mathrm{M}=$ nominal money supply, $\mathrm{P}=$ price level, $\tau=$ term premium $>0, \mathrm{E}(\mathrm{r})=$ the expectation of $\mathrm{r}$, and $\alpha \in(0,1)$, a parameter. Also, $\mathrm{C}(\cdot)=$ consumption functionwith $0<\mathrm{C}^{\prime}<$ $1, \mathrm{I}(\cdot)=$ investment function with $\mathrm{I}^{\prime}<0$, and $\mathrm{L}(\mathrm{r}, \mathrm{Y})=$ demand function for real money with $\mathrm{Lr}<0$ and $\mathrm{LY}>0$. Equations (1) and (2) represent the standard IS and LM curves, and (3) describes the term structure of interest rates that links the long-term interest rate to the short-term interest rate in terms of the expectations theory as well as the liquidity premium theory (a.k.a. preferred habitat theory). The setup as characterized by (1)-(3) is referred to as the extended IS-LM model with the term structure of interest rates. 4

Given the values of all exogenous variables and

${ }^{3}$ Romer [10] has shown the equivalence between the two treatments in this regard.

${ }^{4}$ Blanchard and Fisher [5] developed such a model to study the effects of a change in fiscal policy such as the 1981-1983 tax cuts. But they did not explicitly label both the long-term and the short-term interest rates in their graphic analysis; instead, the short-term rate was eliminated and indirectly represented by the long-term rate in terms of the term structure and Fisher equation. Hence, their treatment did not explicitly present yield curve in the picture. parameters, the equilibrium $\mathrm{Y}^{*}, \mathrm{r}^{*}$ and $\mathrm{R}^{*}$ can be solved from the model as described above. As illustrated in Fig. 1, $\mathrm{r}$ and $\mathrm{R}$ are unequal in equilibrium; their gap is determined by the term premium $\tau$ and the expectation $\mathrm{E}(\mathrm{r})$ as indicated in (3). Note that the equilibrium output is not as usually given at the intersection of the IS curve and the LM curve. Rather, it looks like the equilibrium in a demand-and-supply model with a sales tax.

With a shock or a policy change in the product market or in the money market, it causes a shift in the IS curve or in the LM curve, respectively, as well as possible changes in $\mathrm{E}(\mathrm{r})$ that leads the economy to a new equilibrium. The comparative static analysis in this extended IS-LM model is standard; it compares the resulting new equilibrium with the initial one to check what happens in $\mathrm{Y}, \mathrm{R}$ and $\mathrm{r}$.

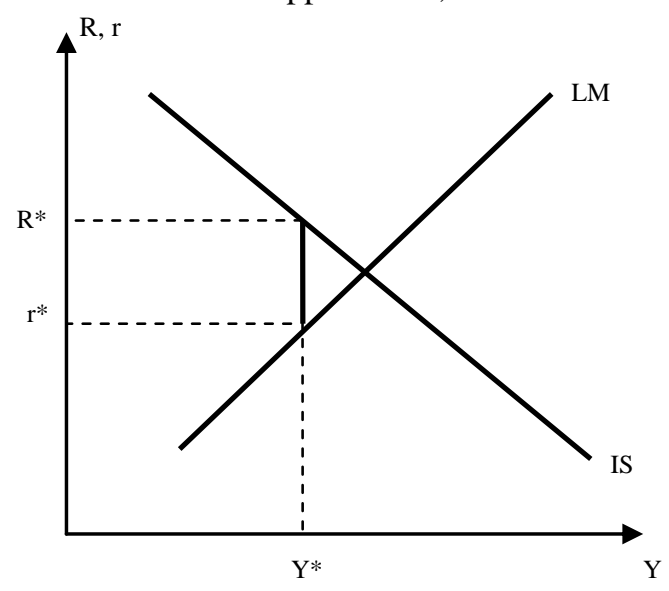

Fig.1. An IS-LM model with term structure

Our main theme here is not the comparative static analysis in this extended IS-LM model. Instead, we want to examine the adjustment process of the long-term interest rate and the short-term interest rate as well as the output between the two equilibria before and after a shock or a policy change, allowing $\tau$ and $\mathrm{E}(\mathrm{r})$ to vary in the adjustment process as well. This is issue is analyzed in the next section.

\section{THE DYNAMIC ADJUSTMENT PROCESS}

The adjustment processes of three variables, $\mathrm{Y}, \mathrm{R}$ and $\mathrm{r}$ are characterized as follows:

$$
\begin{aligned}
& \frac{d Y}{d t}=\varphi[\mathrm{C}(\mathrm{Y}-\mathrm{T})+\mathrm{I}(\mathrm{R})+\mathrm{G}-\mathrm{Y}], \varphi>0, \\
& \frac{d r}{d t}=\left[\frac{d M}{d t}-\mathrm{L}_{\mathrm{Y}} \frac{d Y}{d t}\right] / \mathrm{L}_{\mathrm{r}}, \\
& \frac{d R}{d t}=\frac{d \tau}{d t}+(1-\alpha) \frac{d r}{d t}+\alpha \frac{d E(r)}{d t}, \quad \alpha \in(0,1), \\
& \text { where } \\
& \frac{d \tau}{d t}=\eta[\mathrm{I}(\mathrm{R})-(\mathrm{Y}-\mathrm{C}(\mathrm{Y}-\mathrm{T})-\mathrm{G})], \eta>0 .
\end{aligned}
$$

The adjustment process for the output employs the standard Keynesian approach that "spending determines the income", as indicated in (4) with $\varphi>0$. And the adjustment process for the short-term interest rate as characterized in (5) is derived from (2), since it is assumed that $r$ is always on the LM curve. This assumption can be justified by the fact that the Fed sets the targeted federal funds rate by adjusting 
money supply through the Open Market Operations so as to keep the rate as targeted. However, as Y or M changes, $r$ may change by either moving along the LM curve or jumping with it. Since the short-term rate $r$ is always on the LM curve, whenever an off-equilibrium combination of $(\mathrm{Y}, \mathrm{R})$ is below the LM curve, it indicates that the corresponding yield curve becomes inverted. What is more, when the $(\mathrm{Y}, \mathrm{R})$ combination is on the right hand side of the IS curve and below the LM curve, the output tends to decrease with the yield curve inverted.

Equations (6) and (7) jointly characterize the dynamic adjustment process of the long-term interest rate $\mathrm{R}$; it is driven by two forces: one moves R toward the LM curve, whereas the other shifts it toward the IS curve. On one hand, equation (6) explains how $\mathrm{R}$ may adjust with $\mathrm{r}$ if the latter changes, given the value of all other variables and parameters in (6). Since $r$ is always on the LM curve, it implies that a change in $r$ is due to a shift in the LM curve. When it happens, this force tends to pull R vertically toward the LM curve; the further away $\mathrm{R}$ is from the LM curve, the stronger this force is. On the other hand, equation (6) is the dynamic version of (3) by the preferred habitat theory that combines the expectations theory and the segmented markets theory, implicitly assuming that the representative agent prefers the short-term bond over the long-term bond, i.e., $\tau>0$. In theory the parity in (3) is explained by the arbitrage activity between the two markets, given such a preference. When the system is off equilibrium, the mechanism behind the dynamic process of $\tau$ must be, by nature, the adjustment in $R$ and $r$. Note that $r$ is always on the LM curve, i.e., it is always in the equilibrium Hence, only $\mathrm{R}$ adjusts in the loanable funds market, wherein a surplus pulls $\mathrm{R}$ down and a shortage pushes it up. In other word, the market adjustment force tends to steer $\mathrm{R}$ vertically toward the IS curve. What is more, the further away $\mathrm{R}$ is from the IS curve, the stronger this force is. As a result, these two forces may move the long-term rate $\mathrm{R}$ differently in mechanisms as well as in directions. Nonetheless, it is their resultant that determines the direction and magnitude of $\mathrm{dR} / \mathrm{dt}$, as how component forces form their resultant in physics. Setting $\mathrm{dR} / \mathrm{dt}=0$, we obtain the "R-rest" curve in the $\mathrm{Y}-\mathrm{R}$ space. By construction, this curve must pass through the equilibrium $\left(\mathrm{Y}^{*}, \mathrm{R}^{*}\right)$ as shown in Fig.2.

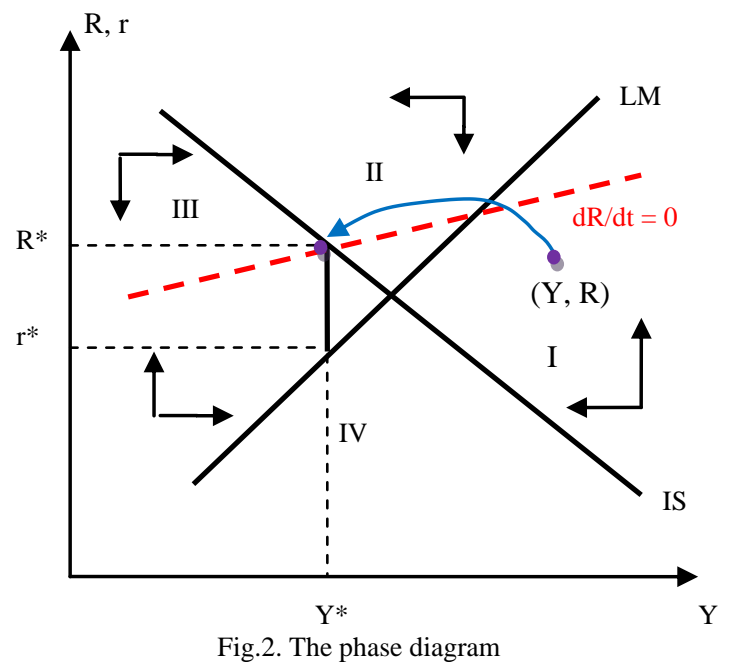

The phase diagram can be drawn from the above discussion on the dynamic adjustment process of $\mathrm{Y}$ and $\mathrm{R}$. The IS curve and the "R-rest" curve (i.e., the one determined by $\mathrm{dR} / \mathrm{dt}=0$ ) divide the $\mathrm{Y}-\mathrm{R}$ space into four areas, labeled $\mathrm{I}$, II, III and IV in Fig.2. Equation (4) reveals that at any point off the IS curve the corresponding output $\mathrm{Y}$ would move toward the IS curve horizontally. On the other hand, at any point off the "R-rest" curve, the long-term rate $\mathrm{R}$ is inclined to adjust toward the curve vertically. This is because the IS curve pulls the long rate $\mathrm{R}$ toward it, i.e., $\mathrm{d} \tau / \mathrm{dt}$ as given in (7), while the curve that is parallel to the LM curve and crosses over $\left(\mathrm{Y}^{*}, \mathrm{R}^{*}\right)$ also drags the long rate $\mathrm{R}$ toward it, i.e., the two terms other than $\mathrm{d} \tau / \mathrm{dt}$ in (6). Also, each of these two forces gets weaker as $\mathrm{R}$ moves closer to the curve. Hence, the long-term rate $\mathrm{R}$ tends to move toward the "R-rest" curve as constructed. As a result, the equilibrium $\left(\mathrm{Y}^{*}, \mathrm{R}^{*}\right)$ is globally stable, also as illustratedin Fig.2.

It is of particular interest when an off-equilibrium $(\mathrm{Y}, \mathrm{R})$ is in areas I and II but below the LM curve. The output $\mathrm{Y}$ is going to decrease with the yield curve inverted; what is more, it may take (quite) a while for it to pass through the LM curve and finally reach the new equilibrium on the IS curve. If the new equilibrium represents the final position of an economic contraction, the above phase diagram and the path of (Y, R) can well explain why an inverted yield curve may lead a recession with a time interval. Empirical evidences show that an inverted yield curve had occurred about 12 months before a recession actually arrived. By official definition of a recession, it occurs after the output consecutively goes down for at least two quarters. Hence, when $(\mathrm{Y}, \mathrm{R})$ combination is still in area I or II and below the LM curve under an adverse shock, the yield curve starts to be inverted but the recession has not been "officially" observed, yet. It would take some time for $(\mathrm{Y}, \mathrm{R})$ to move from area I, maybe via area II, to finally reach the new equilibrium that characterizes the recession.

Note that the above-developed phase diagram of off-equilibrium $(\mathrm{Y}, \mathrm{R})$ is quite general; we don't need to rely on the assumption that the long-term bond be a consol, as usually treated in the literature, and the equilibrium $\left(\mathrm{Y}^{*}, \mathrm{R}^{*}\right)$ is globally stable, rather than a saddle point.

The key element in the above modeling is the dynamic adjustment process in the long-term interest rate $\mathrm{R}$ that leads to the globally stable equilibrium in the phase-diagram analysis. The two forces that drive $\mathrm{R}$ are based on two different mechanisms: the behavior of $\mathrm{d} \tau / \mathrm{dt}$ is based on a market approach - the market force adjust it toward the equilibrium, exactly like what drives $\mathrm{dY} / \mathrm{dt}$, while the rest explanation for $\mathrm{dR} / \mathrm{dt}$ is based on arbitrage in a representative agent approach. Conceptually, arbitrage tends to work whenever there is a gap in price between two markets, no matter whether the two markets are in equilibrium or not, whereas the market forces would adjust the price toward equilibrium. Hence, when the economy is out of equilibrium, $\mathrm{dR} / \mathrm{dt} \neq 0$ and both forces will play a role in adjusting $\mathrm{R}$.

\section{THE ANALYSIS AND THE MAIN RESULTS}

The core issue addressed in this paper is why an inverted yield curve can serve as a leading indicator of a recession? 
Other related questions include: Does inverted yield curve only occur under an adverse shock in the money market? Would it also arise with an adverse shock in the goods market? With the LM curve shifting leftwards, is inverted yield curve caused by a restrictive monetary policy exclusively? Can it also be due to an adverse shock in money market for other reasons? Can a recession arise without following inverted yield curve? Does inverted yield curve always lead a recession? Can yield curve be inverted without any shock? If so, does it lead to a recession?

With the framework developed in the last section, we are now ready to examine those questions addressed above one by one, starting with the case of an adverse shock in the money market.

\section{A. An adverse shock in the money market due to a restrictive monetary policy.}

Suppose that the central bank moves toward a more restrictive monetary policy that raises the short-term interest rate by lowering the money supply. It shifts the LM curve leftwards and hence $\mathrm{dr} / \mathrm{dt}>0$, since $\mathrm{Lr}<0$ from (6). Then, $\mathrm{dr} / \mathrm{dt}$ would remain nonnegative if the policy continues, since the interest rate, e.g., the federal funds rate in the US, is changed discretely and periodically. If the expectation on the future short rate does not completely offset such an effect, we have $\mathrm{dR} / \mathrm{dt}-\mathrm{d} \tau / \mathrm{dt}>0$ and hence, it drags $\mathrm{R}$ into area I and below the LM curve. As shown in Fig.3, the yield curve becomes inverted even before the output starts to decrease along the path for combination $(\mathrm{Y}, \mathrm{R})$ move toward the new equilibrium $\left(Y_{2}^{*}, R_{2}^{*}\right)$. Therefore, an inverted yield curve arises prior to the subsequent recession.

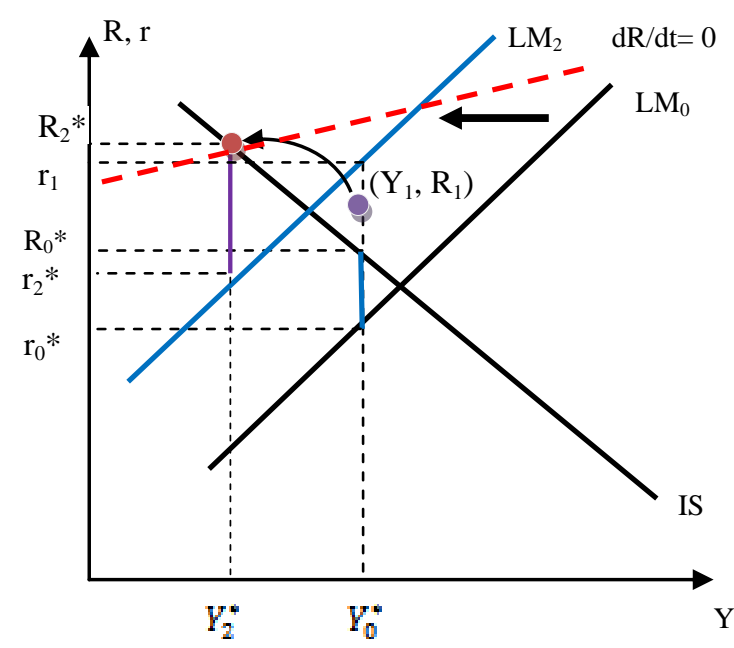

Fig.3. Yield curve under an adverse LM shock

The phase-diagram analysis shows that the restrictive monetary policy not only triggers the consequent recession, but also gives rise to the inverted yield curve quite a while before the recession arrives. In this case, clearly, the inverted yield curve itself is a result of the adverse shock due to restrictive monetary policy and it occurs ahead of the succeeding recession.

\section{B. Adverse shock in the goods market.}

Suppose that there is an adverse shock in the product market. Then, the IS curve shifts to the left, as shown in Fig.4. Initially, the short-term rate $r$ does not change at $Y={ }^{*}$, if no monetary policy is conducted. But the long-term rate $\mathrm{R}$ may drop, more or less, since $\mathrm{d} \tau / \mathrm{dt}<0$ as the (new) IS curve is below the current position of $\mathrm{R}$. The output $\mathrm{Y}$ starts to reduce with the yield curve inverted, if $(Y, R)$ is at point a, or without the yield curve inverted, if at point $b$. Either way, a recession will arrive.

Therefore, an adverse shock in the goods market may cause the yield curve to be inverted. If it happens, it involves a drop in the long rate, rather than a raise in the short rate, as shown by point a in Fig.4. It is also possible, on the other hand, that the adverse shock does not trigger an inverted yield curve, but nevertheless leads to a recession, as characterized by the path starting from point $b$ in Fig. 4. This case may well explain why the two recessions in 1950's and 1960's occurred with no signal of an inverted yield curve.

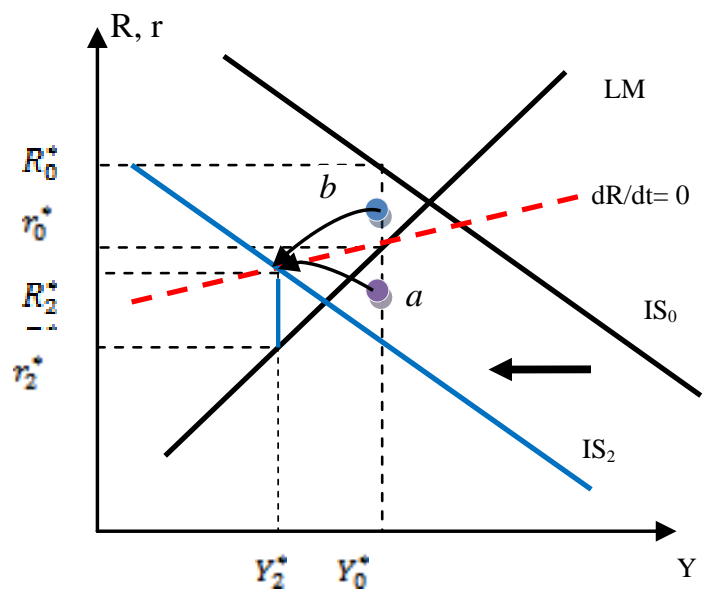

Fig.4. The yield curve with an adverse IS shock

C. Does an inverted yield curve always lead a recession? Should the restrictive monetary policy always be responsible for recessions?

We now address these two related issues. Suppose that there is an adverse shock in the money market but not due to a restrictive monetary policy. Namely, the LM curve somehow shifts leftward, even if the central bank did not mean to raise the short-term interest rate. If the central bank does not take action, the short-term interest rate will rise nonetheless. As a result, the yield curve may become inverted as if the central bank raised the short-term interest rate. If instead, the central bank manages to maintain the short rate at the original level before the shock, then the LM curve would shift back, soon enough. In this case, that is, as long as there is no adverse shock in the product market, the IS curve remains unchanged; a potential recession exclusively due to an adverse shock in the money market could be avoided. The yield curve, however, may be still inverted for a short period, although it is not followed by a subsequent recession. This analysis may well explain what happened in 1998-1999 when the yield curve became inverted briefly. Note that a later recession in 2001-2003 actually followed a second round of inverted yield curve in 2000 .

However, the adverse shock in the money market may accompany with an adverse shock in the product market simultaneously, i.e., both the LM and IS curves shift leftward. In this case, even if the central bank immediately conducts an expansionary policy by cutting the short-term rate, the 
recession may still take place, following an inverted yield curve.

Therefore, the central bank may be responsible for a recession, if (1) it acts too late or ineffectively under an adverse in the money market, or (2) it actually triggers the resulting recession by a hard-landing restrictive monetary policy, although in both cases the yield curve may be inverted On the other hand, the central bank should not be responsible for a recession caused by an adverse shock in the product market, in particular, together with an adverse shock in the money market at the same time.

D. Does an inverted yield curve lead or lead to a recession?

In all three subcases discussed above, the yield curve may become inverted after an adverse shock either in the money market or in the product market, or both and it is an off-equilibrium phenomenon in the dynamic adjustment process. Though it appears ahead of the subsequent recession, the inverted yield curve itself is only a by-product of an adverse shock as discussed above.

Then, can the yield curve become inverted without an adverse shock in either IS or LM curve? If so, can it lead to a recession? In theory, it is possible for the yield curve to be inverted without an adverse shock, if the expectation of $r$ changes significantly. Suppose that the long-term rate $\mathrm{R}<\mathrm{r}$ simply due to such a change in the expected short rate. Then, the combination of $(\mathrm{Y}, \mathrm{R})$ must be below the LM and hence also below the IS curve. In this case, the output $\mathrm{Y}$ will start to increase but not decrease. Therefore, an inverted yield curve may lead a recession, but it can never lead to a recession.

\section{E. Summary of the results.}

We now summarize the above discussions. The possible combinations in the sequence of moves between an inverted yield curve and a recession are:

1) The yield curve becomes inverted and then a recession arises (most cases);

2) The yield curve is inverted, but no recession follows (the event around 1998-1999);

3) The yield curve is not inverted, a recession occurs nonetheless (recessions in 1950 and 1960).

With the model developed in this note (as shown in Fig.2), we have consistently explained all of these three possible observations in a unified framework.

\section{CONCLUDING REMARKS}

This note attempts to explain why an inverted yield curve can be a leading indicator of a recession in a graphic analysis. We developed a modified version of the extended IS-LM model with the term structure (Blanchard and Fischer [6]). With such a framework, we provide a phase-diagram analysis to illuminate how an adverse shock may result in an inverted yield curve as well as a subsequent recession. The phase-diagram analysis of off-equilibrium (Y, R) here is different from those in previous studies. We model the adjustment process for long-term interest rate based on two component forces, instead of only one. It is their resultant force that determines how the long rate is adjusted. This treatment allows us not to rely on an assumption that the long-term bond be a consol, as usually adopted in the literature. What is more, the resultant force helps us draw a different phase diagram that results in a globally stable equilibrium $\left(\mathrm{Y}^{*}, \mathrm{R}^{*}\right)$, rather than the one with a saddle point as in [6]. Another key technical assumption made in this note is that the short-term interest rate is always on the LM curve, which helps us easily see the "shape" of the yield curve along the path of an off-equilibrium (Y, R). Finally, it is worthwhile to emphasize that the occurrence of inverted yield curve is an off-equilibrium phenomenon in the dynamic adjustment process after an adverse shock. That is, an inverted yield curve itself is a by-product of an adverse shock, but occurs ahead of the recession. Hence, it only leads, but does not lead to, the succeeding recession.

\section{ACKNOWLEDGMENT}

The authors thank Richard Cebula and an anonymous referee for their comments on earlier versions of this paper. The standard disclaimer applies.

\section{REFERENCES}

[1] A. Estrella and G.A. Hardouvelis, "Term Structure as a Predictor of Real Economic Activity," J of Fin, 46(2); 1991: 555-76.

[2] A. Estrella and F.S. Mishkin, "The Term Structure of Interest Rates and its Role in Monetary Policy for the European Central Bank," Eur Econ Rev, 41; 1997: 1375-1401.

[3] J.M. Berk, "The Information Content of the Yield Curve for Monetary Policy: A Survey,” De Economist, 146(2); 1998: 303-20.

[4] A. Estrella, "Why does the yield curve predict output and inflation?" The Economic Journal, 115(July); 2005: 722-744

[5] A. Estrella, "The yield curve as a leading indicator: Frequently asked questions," Available: http://www.ny.frb.org/research/capital_markets/ycfaq.pdf

[6] O.J. Blanchard and S. Fisher, Lectures on Macroeconomics, Cambridge, MA: MIT Press 1989, 532-536

[7] W.H. Fisher and S.J. Turnovsky, "The Term Structure of Interest Rates: An Intertemporal Optimizing Analysis," J of Money, Credit, and Banking, 24(1); 1992: 1-26.

[8] G. Hubbard, Money, the Financial System, and the Economy, 6th ed., Boston, MA: Pearson Addison Wesley, 2007: 144-149

[9] L.M. Ball, Money, Banking, and Financial Markets, New York, NY: Worth Publishers, 2009: 104-105

[10] D. Romer, Macroeconomic Theory, 3rd ed., New York, NY: McGraw-Hill Irwin, 2008: 226-227

[11] K.M. Carlson and R.W. Spencer, "Crowding Out and its Critics," Fed Res Bank of St. Louis Rev, 57(2); 1975: 2-17.

[12] R.J. Cebula, "The Deficit Problem in Perspective," Lexington, MA: Lexington Books, 1987. 